\section{Método da} lembrança estimulada: uma ferramenta de investigação sobre aprendizagem em museus de ciências

\section{The stimulated recall method: a research tool applicable to learning at science museums}

\section{Douglas Falcão}

Pesquisador do Museu de Astronomia

e Ciência Afins (Mast)

Rua General Bruce, 586

20921-030 - Rio de Janeiro - RJ

dsfalcao@hotmail.com e dfalcaosilva@reading.ac.uk

\section{John Gilbert}

University of Reading School of Education Bulmershe Court Woodlands Avenue Earlay, Reading RG6 1 HY room B143 England j.k.gilbert@reading.ac.uk
FALCÃO, D.; GILBERT, J.: Método da lembrança estimulada: uma ferramenta de investigação sobre aprendizagem em museus de ciências.

História, Ciências, Saúde-Manguinhos, v. 12 (suplemento), p. 93-115, 2005.

O presente artigo relata uma pesquisa preliminar de desenvolvimento de uma ferramenta metodológica, voltada para as especificidades de estudos sobre aprendizagem em contextos não formais de educação. A pesquisa foi realizada em dois museus de ciências, com uso de uma versão modificada do método da lembrança estimulada (LE). Fotos digitais substituíram o uso tradicional do vídeo na última fase, na qual oito entrevistas foram conduzidas com resultados satisfatórios. As fotos digitais estimularam com eficácia e eficiência os visitantes a narrar suas experiências e expressar os significados que desenvolveram a partir de suas interações com as unidades expositivas.

PALAVRAS-CHAVE: metodologia, lembrança estimulada, aprendizagem em museus.

FALCÃO, D.; GILBERT, J.: The stimulated recall method: a research tool applicable to learning at science museums.

História, Ciências, Saúde-Manguinhos, v. 12 (supplement), p. 93-115, 2005.

The article reports on preliminary research aimed at developing a methodological tool applicable to studies of learning in informal educational settings. The study was conducted at two science museums, using a modified version of the stimulated recall method. Digital photographs replaced the traditional video in the final phase, during which eight interviews were conducted, with satisfactory results. The digital photos efficaciously and efficiently stimulated visitors to narrate their experiences and to convey the meanings they took with them from their interactions with the exhibits.

KEYWORDS: methodology, stimulated recall, learning at museums. 


\section{O que é o método da lembrança estimulada?}

método da lembrança estimulada (LE) foi desenvolvido inicialmente por Bloom (1953), no início da década de 1950, para reavivar as lembranças de estudantes após a aula, ou, segundo as palavras do autor, "lembrar os pensamentos que ocorriam no seu transcurso". Atualmente o termo se refere a um grupo de métodos de pesquisa em que o sujeito é exposto a registros (audioteipes, fotografias, videoteipes, escritos, desenhos) relacionados a uma atividade específica da qual participou (aulas, conferências, sessão de análise etc.). Entende-se que os registros funcionam como pistas que capacitam os participantes a se lembrarem de um episódio em que tiveram uma experiência específica, tornando-os capazes de expressar verbalmente os pensamentos que desenvolveram durante a atividade, assim como quaisquer crenças relevantes, concepçõese comentários em geral. Recomenda-se que a entrevista ocorra logo após o término da atividade em foco. A metodologia provou ser frutífera em diferentes áreas de conhecimento, tais como lingüística, psicologia e estudos sobre o conhecimento prático de professores (Bosher, 1998; Masahiko e Norihiko, 1992; Ritchie, 1999).

Embora a LE seja usada há muitos anos, questões relativas a seu impacto, sua validade e confiabilidade ainda merecem atenção. Fernández e Ruíz (1996) sugerem que, quando usada com professores, a gravação da atuação destes em sala de aula pode causar tensão e, portanto, interferir na autoconfiança e no desempenho. Entretanto, supõe-se que a familiarização do participante com a própria metodologia e o estabelecimento de uma relação de confiança mútua entre este e o pesquisador podem minimizar o impacto do uso do vídeo (Calderhead,1981).

Uma outra questão diz respeito ao nível de consciência dos indivíduos sobre os diferentes tipos de ações. Muitas delas podem acontecer com baixos níveis de consciência ou mesmo sem nenhuma. Alguns autores argumentam que a metodologia da LE não consegue revelar o pensamento por trás de tais ações. Sharp e Green (1975) endossam tal perspectiva e afirmam que algumas áreas do conhecimento pessoal não podem ser verbalizadas.

Schank e Abelson (1977) fazem uma distinção clara entre planejamento e script. O primeiro é um processo consciente, ponderado e, portanto, pode ser mais facilmente automonitorado. Um scripté algo basicamente inconsciente e ocorre quando uma atividade é rotineira e 'excessivamente' aprendida; logo, seria um planejamento já internalizado e de difícil acesso para a LE. Tal questão é relevante quando a metodologia é aplicada em professores, já que é desta última natureza uma boa parcela de suas ações.

Argumentamos, porém, que visitantes de um museu de ciências geralmente estão imersos em um contexto de exploração eminente- 
mente desconhecido, no qual quase sempre inexiste um planejamento anterior a guiar suas ações no transcurso das interações. Por isso, as atividades experienciadas pelos visitantes não podem ser entendidas como planejadas e muito menos rotineiras.

A forma com que os participantes são preparados para as perguntas da entrevista é importante, uma vez que relatos verbais de pensamentos são facilmente influenciados. Alguns argumentam (e. g. Oppenheim, 1992) que, se os respondentes identificarem os objetivos do pesquisador, é possível que expressem um comportamento no qual tentam compactuar com as expectativas dele. Por outro lado, é eticamente aconselhável que o pesquisador esclareça o contexto e o propósito da pesquisa, tendo em mente que não deve dirigir o participante a racionalizações post hoc.

Calderhead (1981) levanta uma série de questões sobre a interpretação dos dados de sessões de LE. Outros autores ponderam que, mesmo quando os pensamentos dos participantes expressamse tão plenamente quanto possível e sem vieses, ainda permanecem perguntas tais como: podem os relatos advindos da LE serem tomados como reais pensamentos transcorridos durante um acontecimento específico? Todas as espécies de escolhas e ações não rotineiras são passíveis de racionalização? As razões expressas pelos participantes para seu comportamento constituem explicações válidas para os propósitos dos pesquisadores?

Bloom (1953) e Gaier (1954) examinaram a extensão com que participantes podem recordar detalhadamente comportamentos verificáveis (passíveis de observação externa). Obtiveram resultados altamente positivos e declararam, por inferência, ser possível a lembrança acurada de comportamentos cognitivos não verificáveis. Ainda assim, permanecem fontes de invalidade (por exemplo, quando o participante tenta melhorar sua 'imagem' distorcendo ou censurando suas declarações). Por outro lado, a análise da consistência interna dos dados pode indicar o nível de validade destes. Não obstante todas essas considerações, o pesquisador deve considerar, em geral, os dados confiantes. Ainda não se inventou uma máquina de ler pensamentos, e se o pesquisador deseja ter acesso ao que as pessoas têm em mente, é necessário que pergunte a elas.

Gass e Mackey (2000) analisam questões relativas à validade e confiabilidade no uso da LE - discutidas por Nisbert e Wilson (1977), White (1980), Ericson e Simon (1980), Anderson (1985), Boritz (1986), Russo et al. (1989), Biggs et al. (1993) e Ericson e Simon (1996) - e concluem: “Estes estudos sugerem (...) que questões de validade e confiabilidade, ainda que controversas, não são sérios obstáculos [ao uso do método]". A qualidade de relatos verbais, tal como o produzido no uso da LE, depende basicamente, como em qualquer método introspectivo, da suposição de que fo- 
ram expressos com cuidado e interpretados com plena compreensão das circunstâncias em que foram obtidos.

\section{A LE nos contextos formal e não formal de educação}

Encontram-se poucos exemplos de adoção da LE nas pesquisas sobre aprendizagem em contextos não formais de educação. A vasta maioria de estudos com a metodologia tem o ambiente escolar como contexto. Com o objetivo de situar o uso desta metodologia, apresentamos uma revisão de cinco artigos: dois conduzidos em museus de ciências e três no contexto escolar.

\section{Estudos em museus de ciências}

Stevenson e Bryden (1991) usaram a LE na avaliação de uma exposição interativa que versava sobre oito temas - máscaras, chá, vidro, detetive científico, impressão, mandíbulas, alimento e conchas. As lembranças dos visitantes foram estimuladas por vídeo, que registrava a exposição sem visitantes. Iniciando por uma visão panorâmica, para orientar o participante, focalizava depois cada um dos temas abordados. As imagens tentavam reproduzir tão fielmente quanto possível o que a pessoa acabara de ver. Indivíduos e grupos foram entrevistados ao fim da visita, por meio de perguntas fechadas e abertas, durante pausas específicas do vídeo. Os autores sugerem que um questionário no qual as perguntas fossem geradas a partir das entrevistas poderia ser aplicado a um número maior de visitantes. Os dados obtidos referem-se à natureza, freqüência e racionalizações das decisões tomadas ao longo das interações do visitante com a exposição. Foi possível obter um amplo espectro de dados, tais como: aspectos cognitivos concernentes aos significados atribuídos às unidades expositivas; a percepção, pelo visitante, da exposição em sua totalidade; críticas sobre o posicionamento das unidades expositivas no espaço físico; e se a exibição motivava o visitante a ir ao restante do museu. Os autores declaram que a LE gerou dados valiosos, antes nunca obtidos por eles ao aplicarem outras metodologias.

Stevenson (1991) realizou um estudo na exposição Launch Pad, do London Science Museum, no qual a LE foi usada em conjunto com outras metodologias. Um membro de cada grupo estudado teve o circuito de visita registrado (com o que interagiu e por quanto

${ }^{1}$ Unidades constitutivas das exposições (painéis, instrumentos, modelos pedagógicos, multimídia, performances, objetos etc.) que objetivam comunicar idéias. tempo). Todos os componentes do grupo foram entrevistados imediatamente após a visita. Semanas depois, enviaram-se questionários a cada grupo visitante. Finalmente, cada grupo foi entrevistado aproximadamente seis meses depois, sendo-lhe exibidas, na ocasião, fotos das unidades expositivas.

A análise teve como referência o que foi expresso pelo indivíduo sobre cada unidade expositiva ${ }^{1}$ visitada. Para tanto aplicou-se uma 
grade de análise, desenvolvida inicialmente para estudos em lingüística e, posteriormente, adaptada para análise de conteúdo de entrevistas sobre reações de estudantes ao ensino de ciências a nível superior. A grade adotada por Stevenson revelou se a unidade expositiva foi recordada ou não; se a lembrança foi espontânea ou estimulada por foto ou comentários de outro membro do grupo; e se a lembrança foi uma mera menção ou houve algum nível de elaboração (clara ou menos clara). Por sua vez, as elaborações foram categorizadas segundo três aspectos gerais: 1 ) descrições (como a unidade expositiva foi usada, ou sobre ela propriamente dita); 2) sentimentos (expressões de prazer, surpresa, chateação ou insatisfação); 3) pensamentos (evidências de julgamentos ou reflexão sobre a unidade expositiva).

As entrevistas resultaram num total de 1.436 comentários sobre unidades expositivas, distribuídos como mostra a Tabela 1.

Tabela I

Distribuição das categorias dos comentários sobre as unidades expositivas

\begin{tabular}{lll}
\hline Categoria & No & $\%$ \\
\hline descrição & 855 & 60 \\
sentimentos & 208 & 14 \\
pensamentos & 373 & 26 \\
\hline
\end{tabular}

Como pode ser observado, $60 \%$ dos comentários foram de natureza descritiva, enquanto os classificados como 'pensamentos' chegam a quase o dobro daqueles considerados 'sentimentos'.

Uma vez que a LE foi usada conjuntamente com outros métodos, não se pode atribuir-lhe exclusivamente os resultados desse estudo. Entretanto, ele pode ser citado como um exemplo de êxito da aplicação dessa metodologia em associação com outras.

\section{Estudos no contexto escolar}

Appleton (1993) recorreu à LE para observar como pequenas mudanças nas aulas são percebidas muito diferentemente pelos estudantes. Ele estudou o comportamento de uma aluna do sétimo ano em duas aulas experimentais de ciências que tratavam de eventos potencialmente geradores de conflito cognitivo - ludião e pêndulos ressonantes. O mesmo professor ministrou ambas as aulas a uma classe de 15 estudantes com habilidades diversas. Proferiu poucas explicações ou comentários, limitando-se a responder às perguntas com 'sim' ou 'não'. Questões que tentavam confirmar ou rejeitar idéias não foram respondidas. As aulas foram gravadas em vídeo. O autor analisou e codificou o comportamento da estudante; os resultados da entrevista e as observações da gravação foram combinados no final análise. Os dados dizem respeito ao 
transcurso dos pensamentos da estudante durante a aula e suas justificativas para as diferenças de comportamento nas aulas. $\mathrm{O}$ uso da LE evidenciou a interferência das diferentes expectativas da estudante na forma com que percebeu as aulas e como o seu comportamento estava sujeito ao contexto. Mostrou também que experimentos concebidos como prováveis geradores de conflitos cognitivos não são necessariamente interpretados como tais.

Marland e Edwards (1986) conduziram uma pesquisa com um grupo de quatro estudantes, em duas aulas de biologia e ciências sociais do ensino médio. O objetivo era conhecer os pensamentos dos jovens ao longo das aulas. Os dados foram coletados na escola e as gravações em vídeo realizadas nas salas usadas regularmente em cada disciplina. Foi solicitado aos professores que não modificassem seus planejamentos rotineiros. (Os autores admitem que a presença de uma câmera e um técnico perturbou inevitavelmente $\mathrm{o}$ processo de coleta de dados, mas tal influência foi admitida como intrínseca ao método.) A LE revelou quão idiossincráticos são os pensamentos dos estudantes numa sala de aula. Segundo a pesquisa, eles variaram drasticamente, tanto de foco quanto no que se refere a processos mentais, e de tal modo que foi impossível identificar tendências gerais. Houve total divergência, até mesmo em tópicos específicos de uma aula.

Os processos de informação dos estudantes foram classificados como: 1) 'no ar' alternando com 'fora do $\mathrm{ar}^{\prime}$, em relação ao que estava acontecendo; 2) monitoramento contínuo do professor; 3) mudanças no nível de processamento da informação, de um estado geral de consciência para uma extrema atenção focalizada, alheando-se temporariamente do que ocorria à sua volta. Já os processos mentais dos alunos foram classificados como: 'interpretativos' (relativos às habilidades culturais necessárias para operar em uma dada cultura, neste caso uma sala de aula); de 'aprendizagem' (reflexões sobre conteúdo de aula); e de 'despistamento' (estratégias para enganar os professores sobre o que estariam fazendo ou pensando).

Butefish (1990) realizou uma pesquisa sobre tomadas de decisão de professores de ciências de ensino médio. O contexto foi um conjunto de aulas iniciais, no qual 17 professores (nove de nível fundamental e oito de nível médio) introduziram um novo conteúdo. Estes foram selecionados por seu ótimo desempenho de ensino, conforme opinião de seus supervisores. Antes da aula o professor participante passou por uma pré-entrevista, a fim de tornar o pesquisador ciente dos objetivos e do planejamento da aula. O passo seguinte foi a gravação em vídeo das aulas. Os dados foram extraídos de entrevistas realizadas com os professores, com base na apresentação do vídeo, e analisados de duas formas: por meio da aplicação de categorias advindas da literatura de tomadas de decisão de professores de primeira à quarta série, com o propósito de compará- 
los a professores de ensino médio; e por um sistema de categorização baseado nos dados da pesquisa. Elaboraram-se os resultados nos seguintes termos: 1) a freqüência das tomadas de decisão e a natureza destas; 2 ) como procedimentos instrucionais (manter estudantes engajados, mudar o ritmo da aula);3) como decisões relacionadas ao aprendiz (recompensa de esforço, reforço a nível individual); e 4) como decisões concernentes ao conteúdo (usar novas analogias, desconsiderar temas planejados).

\section{Comparando uso da $L$ em museus de ciências e na escola}

Nos dois estudos em que museus foram o contexto de pesquisa, a LE foi usada de forma diversa em relação à sua adoção nas escolas. Nos museus, os participantes não se viam na mídia que apresentava os estímulos - vídeo da exposição, no primeiro estudo, e fotos das unidades expositivas, no segundo -, ao contrário do que ocorreu nas pesquisas nas escolas, em que os participantes puderam assistir à gravação de suas atividades. Outra diferença importante emerge da natureza dos dados. Enquanto nas escolas foi dada ênfase aos pensamentos interativos (o que os participantes estariam pensando no transcorrer dos eventos), os dados provenientes dos museus voltaram-se para os significados desenvolvidos pelos participantes durante suas visitas. Argumentamos que tal diferença pode ser explicitamente perseguida, isto é, propomos o uso da LE em museus como uma ferramenta de estímulo à verbalização de significados pessoais das situações experienciadas. Isto não significa, naturalmente, negligenciar os pensamentos dos visitantes transcorridos durante a visita, pois ambos os tipos de dados (significados e pensamentos) costumam ser obtidos no uso dessa metodologia. Aaltonen (2001) afirma que a LE freqüientemente contém tanto dados relativos a relatos de pensamentos quanto a análises sobre $\mathrm{o}$ evento acontecido, embora supostamente o método abra um canal de acesso a pensamentos transcorridos no curso de um evento.

Ao aplicar a LE em museus, deve-se ter em mente que as significações elaboradas pelos visitantes, resultado de suas interações durante a visita, podem esclarecer questões relacionadas à aprendizagem que ocorre nesses locais. Tal perspectiva implica uma redução do tempo decorrido entre a realização das atividades - no caso, a visita ao museu - e a realização da entrevista, pois esse intervalo de tempo é considerado crucial no uso tradicional da LE, já que se busca, sobretudo, resgatar os pensamentos dos participantes.

\section{Aplicando LE em museus de ciências}

Quando LE é aplicada em museus de ciências, passamos a lidar com uma nova categoria de sujeito: o visitante. Mesmo quando se trata de estudantes, nos museus eles estão imersos em um contexto 
social diferente. Não planejam suas ações e escolhas, como professores que preparam um conjunto de aulas, assim como não conduzem suas atividades de forma rotineira. Planejamento requer antecipação de metas e estabelecimento de estratégias; rotina, por sua vez, pressupõe um alto nível de conhecimento e familiarização da atividade.

Um de nós (DF) conduziu três testes a partir de conjuntos distintos de entrevistas, com o objetivo de avaliar o uso da LE em museus de ciências. Os tipos de participantes considerados foram: famílias ou grupos, estudantes e mediadores. As entrevistas duraram de 40 a 60 minutos.

\section{Estratégias de aplicação de LE em museus de ciências}

Com relação aos visitantes, há duas estratégias para coletar dados por meio da LE em museus, cada uma delas com suas especificidades. A primeira consiste em selecionar unidades expositivas que representem categorias previamente definidas (por exemplo, as relativas à aprendizagem), e uma câmera de vídeo grava visitantes de perfis variados em interação somente com essas unidades. Dois aspectos emergem de tal abordagem. Primeiro, é possível controlar o perfil dos sujeitos participantes - só aqueles que se encaixam a um perfil característico são selecionados para o estudo. O segundo aspecto está relacionado à possibilidade de avaliar previamente a qualidade da interação. Apenas os visitantes que indicam boas interações integram a pesquisa, o que descarta de antemão interações totalmente desinteressantes.

Parece-nos, entretanto, que essa abordagem oferece uma visão fragmentada, pois não considera a visita como um todo. Isolar interações específicas do visitante, ignorando as que ele realiza com o restante da exposição, pode acarretar interpretações inválidas. No estudo de aprendizagem em exposições de museus de ciências, se considerarmos as interações do visitante com apenas algumas das unidades expositivas, arriscamo-nos a uma séria distorção, no que diz respeito às possíveis relações entre as características das unidades expositivas e a aprendizagem dos visitantes. As categorias propostas podem privilegiar demasiadamente a perspectiva dos idealizadores, em detrimento do olhar do visitante. Unidades que sejam, em princípio, similares na opinião dos idealizadores podem ser bastante diversas do ponto de vista dos visitantes, e vice-versa. A interpretação do indivíduo sobre uma unidade expositiva em particular pode estar 'contaminada' pela visita a outras unidades, razão por que argumentamos ser necessário atentar para o que acontece ao redor da interação-alvo. Não se pode, portanto, observar exclusivamente a interação do visitante com uma categoria específica de unidade expositiva, mas incluir as demais que ocorrem durante a visita, seja em exibições temáticas, em que se espera 
2 Entendemos por 'fragmentadas' as exposições interativas encontradas em museus de ciências ou science centres, compostas por um agrupamento de unidades expositivas com pouca ou nenhuma relação temática entre si. complementaridade entre as unidades, ou em exposições fragmentadas $^{2}$. Um aspecto importante, nessa abordagem, é o fato de que há mais chances de capturar interações do mesmo visitante com diferentes unidades expositivas, classificadas pelo pesquisador em uma mesma categoria.

A segunda estratégia de coleta de dados por intermédio da LE é projetada para desenhar um quadro mais holístico da visita, em vez de capturar algumas interações específicas. Os visitantes que se enquadram no perfil previamente determinado têm gravadas em vídeo suas interações com cada unidade expositiva, o que permite estudar, de fato, possíveis relações entre diferentes categorias de unidades expositivas e a aprendizagem do visitante. Três aspectos estão associados a esta estratégia: não há meio de selecionar previamente as interações potencialmente 'boas', como na primeira estratégia; o número de interações em cada categoria proposta certamente será diferente; e o número de visitantes por categoria também será diverso. Deixar de selecionar interações potencialmente boas não constitui problema; aliás, podemos obter um quadro mais representativo da variedade de interações entre visitantes e unidades expositivas quando não excluímos interações a priori. Os segundo e terceiro aspectos seriam problemáticos em uma abordagem quantitativa, mas não em um estudo qualitativo, pois tais variações refletem, na verdade, a diversidade das categorias de unidades expositivas presentes nos museus e a natural multiplicidade de interesses do público visitante.

\section{O teste piloto}

Com o objetivo de avaliarmos a LE como ferramenta de investigação da aprendizagem de visitantes em museus de ciências, conduzimos um teste piloto dividido em três fases, em que se registraram as interações entre os visitantes com cada unidade expositiva. Os conjuntos de entrevistas foram realizados em períodos diferentes, mas com propósitos complementares. Nas duas primeiras etapas do teste, a gravação da visita resultou em vídeos com 40 a 60 minutos de duração.

\section{Fase I}

A primeira fase visou a testar a adequação da LE como metodologia para coletar dados sobre aprendizagem em um contexto de museus de ciências. Dois grupos de visitantes foram entrevistados no Museu de Astronomia e Ciências Afins (MAST), no Rio de Janeiro. A primeira entrevista foi realizada com um par de crianças e a segunda, com um casal de adultos. Ambas foram realizadas imediatamente após a visita às exposições, e o vídeo era projetado em uma tela de grandes dimensões. As entrevistas foram gravadas 
${ }^{3}$ Unidades expositivas de natureza interativa, que permitem ao visitante ter algum nível de controle sobre seu comportamento; diferentes ações do visitante levam a diferentes respostas visualmente observáveis. em áudio e posteriormente transcritas, e também registradas em vídeo para fins de apoio à análise das transcrições.

Na primeira parte da entrevista, explicava-se aos visitantes o propósito desta e o que aconteceria: uma conversa informal sobre o que eles haviam descoberto em cada unidade expositiva visitada e no que pensavam enquanto interagiam com ela. Foi realçado que a entrevista não era um teste de conhecimento. $\mathrm{O}$ entrevistador interrompia a exibição do vídeo em certos momentos e questionava os visitantes sobre seus pensamentos naquelas ocasiões, por que tomaram então determinadas atitudes, o significado que atribuíram a cada unidade expositiva etc.

A primeira entrevista foi feita com uma menina e um menino de 7 e 11 anos, respectivamente. Ambos visitaram a exposição enquanto a mãe realizava uma consulta à biblioteca do museu. As crianças foram filmadas, com a permissão da mãe, e percorreram três exibições por conta própria, sem ajuda de mediadores.

Durante a visita e a entrevista, a presença da câmera de vídeo não os perturbou. A visão de si mesmos realizando atividades teve por finalidade estimulá-los a se expressar sobre a visita, nos aspectos específicos (conteúdo das unidades expositivas e pensamentos durante a interação) e gerais (impressões, sentimentos), gerando relatos sobre pensamentos transcorridos durante as interações bem como comentários a respeito de alguns comportamentos observados na visita. Com relação às unidades expositivas que envolvem um comportamento mais dinâmico, ${ }^{3}$ as explicações providas pelos visitantes evidenciaram serem estes influenciados pelos indícios adicionais providos pelo vídeo. Tal problema será discutido mais adiante.

Ambas as crianças declararam ter apreciado suas experiências, e a perspectiva de entretenimento foi constante em toda a entrevista. Perguntas sobre o que haviam pensado geraram respostas que revelavam interesse pelo uso das unidades expositivas. Por vezes as crianças desenvolveram teorias complexas para justificar seu comportamento na interação com algumas das unidades expositivas. Entretanto não puderam justificar outras ações. Por exemplo: diante da gravação em que aparecia usando uma unidade expositiva sobre as estações do ano, e questionada sobre o que havia entendido, a menina respondeu não tê-la compreendido. Na cena seguinte da gravação, a menina abandonava o referido dispositivo, encaminhava-se para outro e, depois de manipulá-lo sem qualquer interesse aparente, dirigia-se novamente ao anterior. Ao ser indagada sobre as razões do retorno à unidade expositiva, cujo uso, segundo suas próprias palavras, não tivera para ela nenhum significado, afirmou simplesmente "porque eu achei legal", sem mencionar qualquer justificativa adicional.

Vale destacar que a pergunta 'O que vocês pensavam naquele momento?' , uma das principais da metodologia, perturbou as crian- 
ças e acarretou-lhes um certo desconforto. Outro aspecto relevante da entrevista foi que o pesquisador, ao mesmo tempo em que a conduzia, observava o vídeo pela primeira vez, quando o ideal seria uma análise precedente da gravação e uma edição resumida dela, com apenas trechos potencialmente interessantes. Mas tal procedimento acarretaria agendar, com os participantes, a entrevista para outro dia que não o da visita, o que originaria outros problemas operacionais.

A segunda entrevista foi realizada com um casal de adultos, ambos com cerca de trinta anos de idade. Ela era assistente social e ele, feirante. A mulher esteve no comando - tal como ocorrera na maior parte da visita -, respondendo às perguntas direta e objetivamente. Teceu comentários claros sobre as interpretações que fez das instruções e o que havia entendido com as interações. O marido limitou-se inicialmente a respostas breves, submetendo-se aos pareceres da esposa. Entretanto, na segunda metade da entrevista, quando as perguntas passaram a tratar de aspectos gerais da visita, ele estendeu seus argumentos e chegou, às vezes, a discordar da mulher. Isto parece indicar ter ela captado melhor os aspectos formais da visita, ao passo que o homem, com um nível menor de escolaridade, sensibilizou-se mais pelas características gerais.

$\mathrm{O}$ trecho a seguir refere-se à parte da entrevista que versa sobre a interação com uma unidade expositiva denominada Erre Se Puder (Figura 1), na qual o visitante é desafiado a errar, ao pôr uma esfera no foco de um perfil parabólico. Cabe a ele escolher uma entre um conjunto de calhas paralelas ao eixo da curva e liberar uma segunda esfera no topo da calha escolhida. Enquanto era entrevistado, o casal assistia ao trecho do vídeo relativo à visita à unidade.

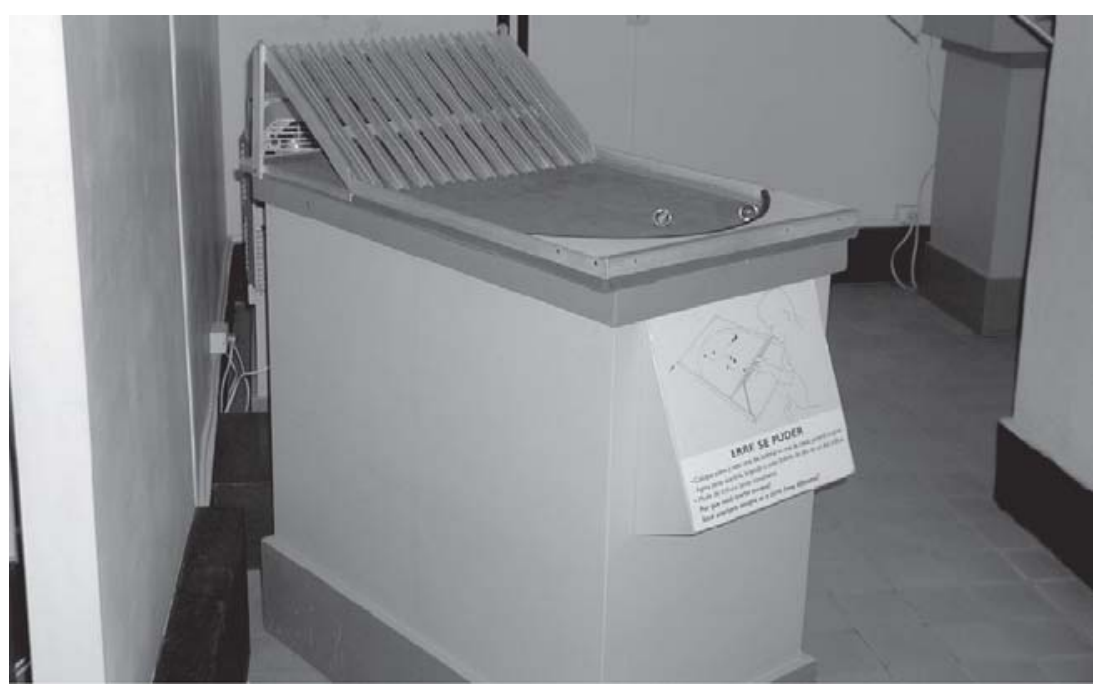

Figura I - Dispositivo Erre Se Puder 
Entrevistador - Por que é tão difícil errar a segunda esfera?

Mulher - Só não entendi essa... Ali no meio [as calhas centrais]... devido à velocidade [da esfera]... Ali onde aquela parte central [foco da parábola], aquela parte central ali... Não sei, creio que ali tem um ímã, alguma coisa... Aquela superfície que... entendeu? Aquilo ali, por ser o ponto central, deve ter alguma coisa ... Um mecanismozinho, alguma coisa.

Neste comentário, observamos a visitante superpor, a princípio, duas explicações. A primeira refere-se à velocidade que a esfera desenvolve ao ser liberada nas calhas centrais ou laterais (que não são calhas de fato, mas quase sempre são usadas como tal pelos visitantes).

Em seguida, o vídeo mostrou imagens em que o casal começava a explorar a unidade expositiva. A mulher abandona a explicação do ímã e aprofunda a explicação baseada na diferença de velocidade:

Agora, ali no meio [calhas], quando a gente joga, a tendência é ela [esfera] ir, porque ela desce com muita velocidade... Como ele [marido] estava tentando jogar pelo canto [falsa calha], como a bola ali penetra totalmente dentro daquele cano ali [a largura da falsa calha é maior do que o diâmetro da bola e por isso ela assenta], acho que aquele ali é mais um acabamento, não é? Por ela descer mais lenta [a esfera desce colidindo com parafusos de fixação], ali no canto ela não chega com tanta força, então ela não dá para alcançar onde no caso ali é a meta, aquele ponto central. Devido ali no meio ela não encaixar naquelas calhas, ela desce com total velocidade.

A seqüência de explicações é coerente com os comentários feitos durante a interação com a unidade expositiva (no vídeo, ouvese o casal conversando ativamente). Ambos os argumentos (presença de um ímã no foco e diferença de velocidade da esfera) foram expressos na visita. A mulher menciona, então, uma terceira explicação:

E na própria mesa tem aquele movimento circular [a parábola propriamente dita], que ajuda. Se ela fosse quadrada ou coisa assim, talvez não. Por ela justamente ser assim, esse movimento circular, ela tem como ajudar a expulsar ela [esfera] para o centro da mesa.

A análise das gravações da visita e da entrevista nos leva a considerar que essa terceira explicação foi fortemente baseada nos novos indícios oferecidos pelo vídeo por ocasião da entrevista. No momento em que tal explicação foi introduzida, a imagem na tela mostrava uma visão frontal da unidade expositiva. É provável que, ao exibir a interação com unidades expositivas dinâmicas, o vídeo dê acesso a pistas não percebidas pelo indivíduo por ocasião da 
visita, o que pode influenciar suas respostas às perguntas sobre o conteúdo dessas unidades.

Os resultados do primeiro teste da LE como instrumento de coleta de dados sobre aprendizagem em exposições de museus de ciências apontam para a validade do método. Nas duas entrevistas, os visitantes reagiram bem ao vídeo em que puderam assistir à sua interação com as unidades expositivas. Porém algumas dificuldades foram identificadas, como veremos adiante.

Um segundo problema potencial, relacionado ao uso da câmera de vídeo, diz respeito aos adultos. Diferentemente das crianças, eles não se sentem à vontade na presença de uma câmera de vídeo a gravar ostensivamente suas ações. Filmar visitantes por toda uma exposição é tarefa difícil, e seguir seus passos com uma câmera de vídeo pode interferir na forma com que eles interagem com as unidades expositivas e entre si.

\section{Fase 2}

Na segunda fase do teste piloto, duas novas categorias de sujeitos foram investigadas: mediadores e estudantes. Foram entrevistados três mediadores e dois estudantes do ensino fundamental. Note-se que os dois grupos constituem categorias bastante distintas entre si: os mediadores pertencem à equipe de trabalho dos museus e têm a função de dar suporte aos visitantes, nas exposições.

O objetivo do teste piloto, com relação aos mediadores, era verificar em que extensão o uso da LE poderia contribuir para trazer à tona estratégias, decisões, ações e explicações implementadas durante o transcurso das visitas. Já com os estudantes, a meta era investigar a adequação do uso da LE em museus como estratégia para fazer emergir aspectos relativos à aprendizagem supostamente adquirida com a visita.

Foram escolhidos para serem entrevistados os estudantes que interagiram mais diretamente com o mediador na parte introdutória da visita, a ele dirigindo respostas e/ou perguntas, ou manifestaram interesse em conversa com colegas durante o percurso da exposição. Pressupôs-se que tais critérios eram indícios de que os estudantes teriam facilidade de expressar suas idéias durante a entrevista. Os dois estudantes selecionados visitaram o MAST com suas respectivas turmas: uma menina de dez anos, estudante da terceira série de uma escola pública; e um menino de 11 anos, aluno da quinta série de uma escola particular.

A entrevista com a menina aconteceu sete dias após a visita, quando ela voltou ao museu com outro grupo de estudantes, enquanto o menino foi entrevistado na própria escola, cinco dias depois da visita. Embora recomende-se, na LE, que a entrevista seja feita tão logo termine o evento investigado, a agenda da escola não permitiu que os estudantes fossem entrevistados naquela ocasião. 


\footnotetext{
${ }^{4}$ Baseada na exploração explícita dessa 'revisita', existe uma metodologia denominada video trace (Stevens, Hall, 1997), em que o vídeo é usado como forma de reexplorar a atividade, justamente pelo fato de oferecer indícios que não foram originalmente acessados pelo participante.
}

Por outro lado, o lapso tornou possível a edição de uma nova versão do vídeo, contendo somente as interações consideradas mais importantes pelo pesquisador. Tal procedimento conferiu maior fruição ao processo da entrevista, a despeito dos riscos de limitação do que é exposto ao entrevistado, conforme mencionamos anteriormente.

As entrevistas com os estudantes confirmaram o que o pesquisador havia percebido nas entrevistas da primeira fase: nas situações em que as unidades expositivas expressam comportamento dinâmico em resposta à ação do visitante, o vídeo proporciona uma experiência adicional. Ou seja, mais do que estímulo à memória, age como uma 'visita extra' ao que foi experienciado. Houve ainda um problema adicional, decorrente do fato de a visita dos estudantes ter sido orientada pelo mediador, cujas explicações eram reproduzidas no vídeo, em alto e bom som, influenciando as respostas sobre os significados atribuídos às unidades expositivas. Em interações com unidades expositivas dessa natureza, o que é visto no vídeo é diferente do que pode ser visto pelo visitante no momento da interação. Assistindo às imagens, ele acessa, eventualmente, elementos que não estavam disponíveis na ocasião da interação original. Nestes casos, as imagens do vídeo oferecem uma revisão dinâmica e holística da experiência. Consideramos tal aspecto um obstáculo potencial ao uso da LE em museus de ciências, quando essa metodologia é aplicada a unidades expositivas que expressam comportamento dinâmico. Por outro lado, não identificamos problemas com unidades expositivas estáticas ou que oferecem baixo grau de controle pelos visitantes.

As considerações feitas indicam uma diferença importante entre a aplicação da LE em atividades 'teóricas' e 'práticas'. Parece-nos que, em uma atividade teórica, os marcos de referência para a memória se dão no nível interpessoal (professor-estudante, visitantemediador, visitante-visitante). Os comentários verbais e as imagens são, em princípio, igualmente importantes, mas os primeiros vão mudando com o passar do tempo, enquanto as imagens pouco se alteram. Nas atividades práticas, os marcos de referência podem acontecer em nível interpessoal, mas estão associados principalmente às ações sobre o dispositivo prático e o comportamento por ele expresso em resposta a tais ações, e por isso mudanças na imagem são marcos contínuos de referência. Por tais motivos entendemos que, no caso do uso da LE em atividades práticas, o vídeo pode vir a ser mais do que uma mera fonte de estímulos à memória. Se as atividades são visualmente dinâmicas, provavelmente haverá elementos no vídeo que não estavam acessíveis aos visitantes por ocasião da interação originalmente experienciada. ${ }^{4}$

Em suma, argumentamos que o uso do vídeo na LE, para as atividades dinâmicas, pode desempenhar um papel que ultrapassa 
a intenção inicial de oferecer uma fonte de estímulos à memória do participante, o que se revelará um problema para pesquisadores que pretendem aplicar esse recurso (tradicional na metodologia) em museus de ciências, dado que esses espaços costumam estar repletos de atividades práticas e dinâmicas.

Outro aspecto do teste piloto a salientar concerne à opção de capturar as interações do visitante com todas as unidades expositivas utilizadas ou com somente algumas delas. Por ocasião da entrevista, entrevistador e participante assistiam juntos ao vídeo da visita, com cerca de 30 a 40 minutos. O processo requer que ambos vejam a fita e selecionem trechos para discussão. No entanto observamos que coube ao pesquisador, na grande maioria das vezes, a iniciativa, pois os participantes raramente se expressavam a esse respeito. Quando o entrevistado não tem nada a dizer sobre uma cena em particular, o pesquisador deve buscar trechos que o sensibilizem. Se houver demora nesse processo a entrevista tende a se prolongar, e o participante pode diminuir seu nível de compromisso com ela.

Com relação aos mediadores, pode-se dizer que o uso tradicional do método da LE em museus de ciências encaixa-se como uma luva. Seu potencial, nesses casos, está evidenciado em trecho extraído da entrevista com uma mediadora do MAST, estudante de pedagogia, quando questionada sobre o critério para a escolha de informações que, apesar de ausentes na exposição, foram agregadas ao seu discurso. Imaginemos uma televisão que exiba imagens da referida mediadora atuando em uma exposição sobre a história da astronomia, com um grupo de estudantes de quinta série do ensino fundamental. $\mathrm{O}$ trecho a seguir da entrevista é relativo à exploração de uma unidade expositiva sobre as grandes navegações.

Entrevistador - E agora você está explorando a parte da exposição que fala das navegações. E o que ficou muito claro é que você busca, o tempo todo, trazer informações que não estão presentes na exposição. Qual é o seu critério de escolha dessas informações?

Mediadora - Procuro informações que posso utilizar depois. Ali eu falo do sextante, eu estou ali só para dizer que eles usavam esses instrumentos para auxiliar as navegações e que precisavam olhar o céu pra isso. Então eu estou só tentando conectar...

Entrevistador - E aquela do Equador? [narrativa sobre os primeiros europeus, que justificavam a baixa estatura de alguns povos habitantes da zona equatorial como efeito do calor e da maior incidência de luz solar]. Deu para perceber que eles ficaram interessados nessa informação.

Mediadora - Isso foi um bolsista que me falou. E durante a visita eu conto umas coisas assim, porque eu vi que história impressiona, qualquer tipo... Então o que eu puder colocar eu vou aproveitando, dependendo da turma eu comento aquele calendário [gra- 
vuras presentes na exposição], dependendo da turma eu conto uma história qualquer que eu lembrar na hora... Ali foi essa, mas poderia ser uma outra coisa.

A resposta revela uma troca de experiências entre mediadores, a funcionar como fonte de narrativas a serem utilizadas conforme o transcurso da mediação. As entrevistas com os mediadores sugerem que a observação do vídeo, no qual se vêem em ação, guiando visitantes pelas exposições, coloca-os em uma perspectiva semelhante àquela de professores, em pesquisas que usam a LE. Eles foram capazes de negociar adequadamente perguntas sobre o seu papel nos museus de ciências, suas estratégias de ação, critérios de escolha para a seleção do uso das unidades expositivas, o motivo de recorrerem a elementos ausentes nas exibições (analogias, explicações gestuais etc.), bem como demonstraram saber administrar eventuais situações de conflito entre os estudantes, dentre outras circunstâncias. A observação das imagens, a escuta de seu próprio discurso e de comentários e perguntas dos estudantes tornam o vídeo uma forma frutífera de exploração da racionalidade das ações dos mediadores.

Por outro lado, por entendermos não ser este o caso quando o recurso é adotado com visitantes de museus de ciências, sejam eles estudantes ou grupos avulsos, propomos uma adaptação da LE nessas circunstâncias. Os problemas identificados nas duas primeiras fases do teste piloto podem ser resumidos nas seguintes perguntas: como estimular o visitante no processo de entrevista sem criar uma 'revisita' ao que foi experienciado? Como registrar imagens das interações dos visitantes assegurando um baixo nível de interferência sobre seu comportamento? Como facilitar a fruição da entrevista, quando as interações com todas as unidades visitadas são abordadas?

\section{Fase 3}

O uso de fotos digitais em lugar do vídeo foi vislumbrado como uma possível solução para os problemas indicados, daí ter sido incluída uma terceira fase de teste, cujo propósito principal foi avaliar a eficácia dessa substituição com visitantes em museus de ciências.

Foram realizadas oito entrevistas (sete estudantes e um grupo familiar). Em todas elas, os participantes externaram comentários sobre o que fizeram e os significados que desenvolveram. Foram capazes de construir narrativas sobre suas visitas, como pode ser comprovado pela entrevista de Pedro, menino de oito anos cursando a segunda série do ensino fundamental de uma escola pública da cidade do Rio de Janeiro, que visitou a exposição Biodescoberta, do Museu da Vida (Casa de Oswaldo Cruz, Fundação Oswaldo 
Cruz), na mesma cidade, juntamente com a sua classe. O trecho de sua entrevista, a seguir, refere-se a uma atividade com microscópios, orientada por um mediador. A entrevista aconteceu na escola do estudante, em horário normal de aula, seis dias depois da visita.

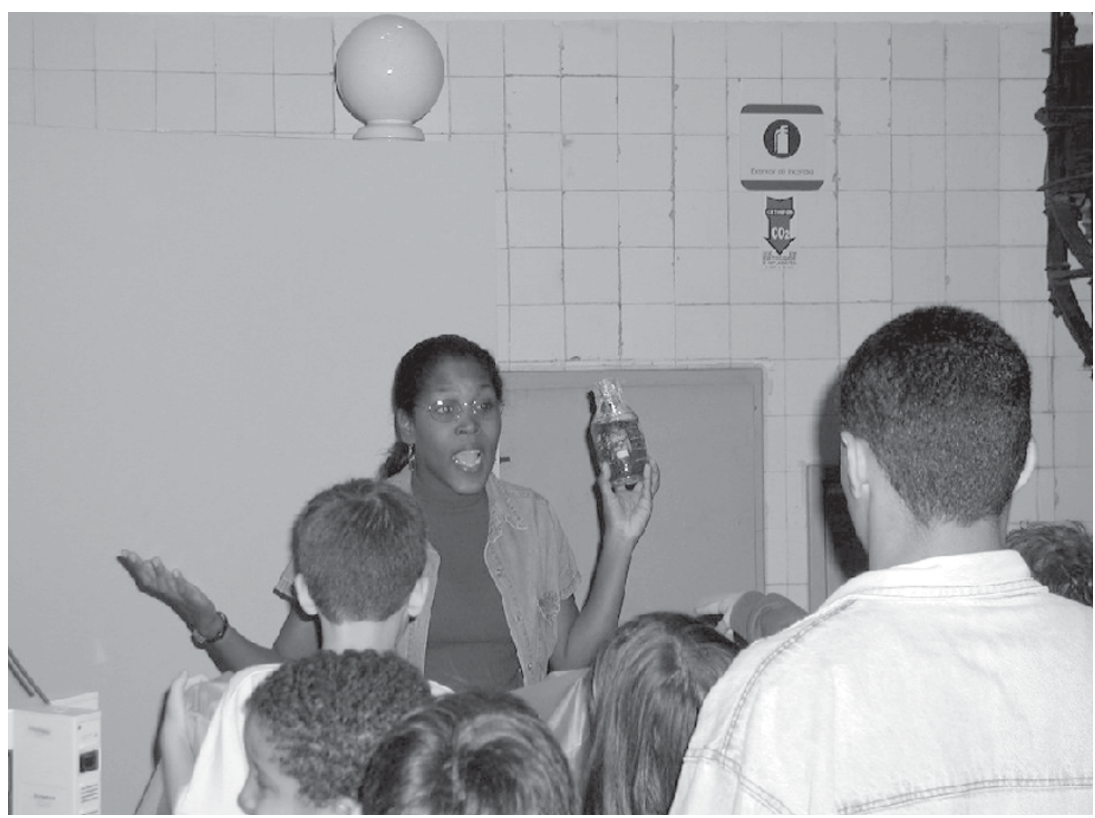

Figura 2 - Oficina de microbiologia - cena 1

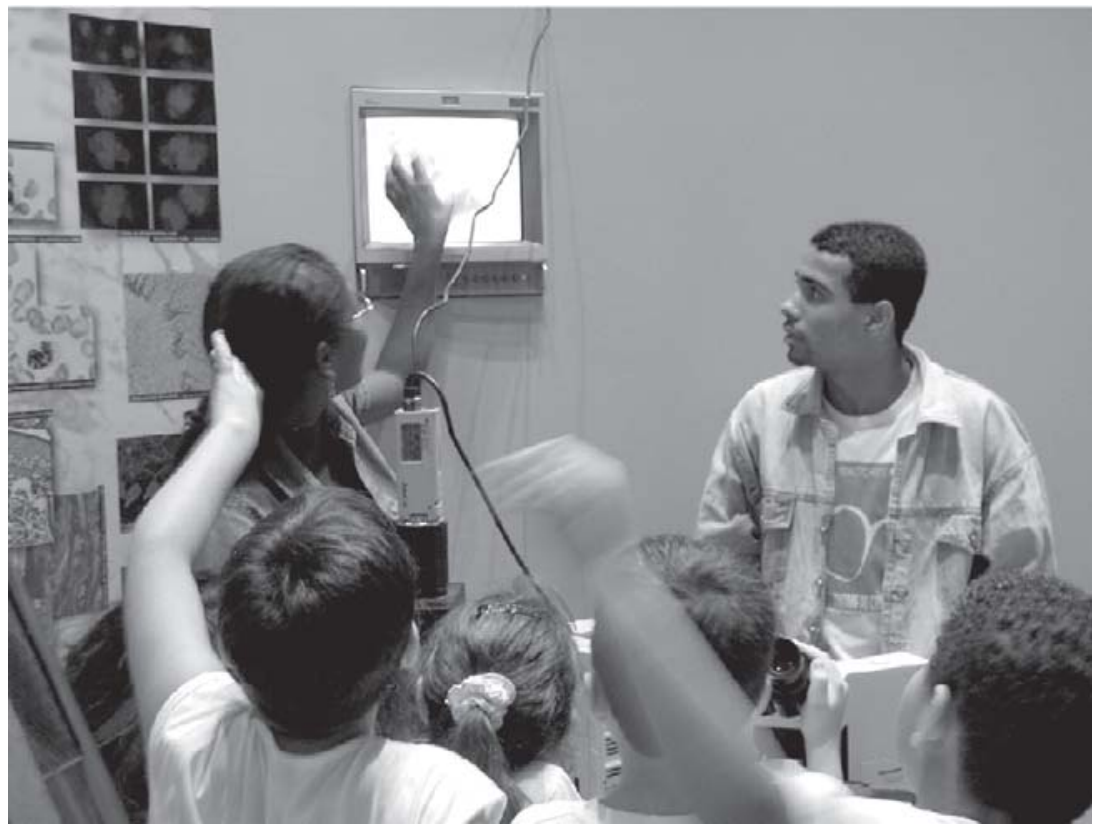

Figura 3 - Oficina de microbiologia - cena 2 
Menino - Dentro desse vaso [Figura 2] daqui tinha uma planta aí. Fui eu, a Camila Lima, Mariana... deixa eu lembrar... o Arthur e o Charles. Nós fomos ali perto... A gente fez a mesma coisa, só que não foi com a célula da boca [atividade anterior]... A gente pegou um pedacinho da planta, botou no vidro [lâmina de microscópio], aí a tia [mediadora] pegou aquele negocinho azul [corante], botou, pegou aquele pedacinho de vidrinho pequeno, botou, aí eu levei lá pra ...

O segmento evidencia que o estudante estava contextualizando a foto, situando-a no nível de suas relações pessoais e enfocando o conteúdo da atividade. No trecho adiante, o menino manifesta compreensão de um importante aspecto do conteúdo da atividade em curso: a necessidade do uso do corante.

Entrevistador - Para que você acha que servia esse negocinho azul aí, que vocês pingavam?

Menino - Porque a célula é transparente, assim não dava pra ver... Por isso botou.

Na parte da entrevista transcrita a seguir, explorava-se a foto da Figura 3. Percebe-se que a visão, no microscópio, de uma mostra de tecido celular gerou um conflito cognitivo na experiência pessoal do estudante.

Entrevistador - Entendi. Vamos ver a próxima [Figura3]. O que você estava falando, aí?

Menino - Ah, é a mesma coisa, não é? [Pausa.] Aí ela [mediadora] está mostrando o negócio da planta.

Entrevistador - Mas olha só, você estava com o braço estendido. Acho que você estava fazendo uma pergunta.

Menino - É...

Entrevistador - Vocêlembra o que era?

Menino - Não lembro. É porque eu pensei que a... a célula da folha não fosse assim toda quadriculada, pensei que fosse linha, linha, linha, linha, linha.

Entrevistador - Ah, tá.

Menino - Só linha.

\section{Entrevistador - Por que você achava isso?}

Menino - Porque quando a gente pega a folha dá para perceber que é toda feita de linha, não é? A gente olha, a gente olha com perfeição! Tinha uma linha aqui [gesticula], aqui, tá?, onde a gente segura, o cabo [gesticula], tem uma linha aqui, uma linha aqui, uma linha aqui, uma linha aqui, uma linha aqui, uma linha aqui, uma linha aqui, uma linha aqui. [gesticula]. 
Entrevistador - E quando no microscópio, o que foi que você viu?

Menino - Aí eu vi que era tudo quadriculado!

O uso de fotos digitais revelou-se positivo e com importantes implicações metodológicas. Com uma câmera digital foi possível registrar todas as interações com as unidades expositivas visitadas. Algumas fotos de cada unidade expositiva visitada foram suficientes para cobrir todo o percurso dos visitantes, incluindo momentos de divertimento e conversas. As fotografias foram tiradas nos momentos potencialmente relevantes de interação com cada unidade expositiva. Nas atividades mediadas e de longa duração (como a de microscopia, por exemplo), registraram-se o início das explicações, as perguntas expressas pelo visitante alvo ou por alguém, o uso do microscópio, conversas com algum companheiro, gestos de interesse ou desinteresse etc. Os visitantes, em geral, tendem a se comportar mais naturalmente na presença da câmera fotográfica do que na presença da câmera de vídeo. Em outras palavras, o uso da primeira é menos 'invasivo' do que o da segunda, aspecto particularmente relevante quando os participantes são adultos.

\section{Comentários finais}

Nos estudos que usam LE nas escolas, as atividades em foco, teóricas ou práticas, acontecem num ambiente isomórfico, isto é, sempre no mesmo lugar, com as mesmas pessoas ao redor e com os mesmos objetos. Na escola, a substituição de vídeo por fotos no uso dessa metodologia pode não ser uma jornada recompensatória. Em uma sala de aula típica, a seqüência de fotos de um estudante teria poucas chances de oferecer referências suficientemente distintas, em relação ao transcurso da aula. Nas imagens fotográficas também estariam ausentes os registros sonoros (a fala do professor e dos estudantes), que certamente constituem fortes marcos de referência para o contexto.

As questões relativas à validade da LE se mostraram bem menos problemáticas quando aplicada em museus de ciências do que na escola. Durante a interação com as unidades expositivas, as atividades do visitante não podem ser classificadas como resultado de um planejamento anterior ou de scripts, como ocorre com o professor em sala de aula. Embora existam eventualmente roteiros que guiem o comportamento dos visitantes (o modo de se comportar em um museu, por exemplo), eles não dão conta da reação às surpresas típicas vivenciadas em um museu de ciências. Tal diferença de contexto pode explicar por que os dados advindos da adoção dessa metodologia em museus de ciências e em escolas tendem a diferir em natureza.

As entrevistas realizadas no teste piloto ratificam a distinção apontada pela comparação dos estudos que usaram a LE na escola e em museus de ciências. Nestes últimos percebeu-se uma dificul- 
dade, por parte dos visitantes, em expressar pensamentos que teriam desenvolvido ao longo da visita, ao passo que a expressão dos significados atribuídos às situações experienciadas ocorreu com fruição. Assim, a julgar pela riqueza de dados provenientes das entrevistas, a aplicação da LE com o uso de fotos, nos dois museus de ciências, mostrou-se uma ferramenta bastante promissora.

Vale destacar que os mediadores expressaram com mais facilidade e freqüência comentários relativos a seus pensamentos durante as ações do que os visitantes. Afirmamos anteriormente que mediadores e visitantes são personagens com papéis bastante distintos. Os primeiros conduzem atividades planejadas e, até certo, ponto de forma rotineira; os visitantes estão a explorar uma nova experiência, em um contexto sobre o qual a informação que detêm é insuficiente para lhes permitir antecipar o que terão pela frente. Muitos visitantes reagiram com desconforto à pergunta 'O que você estava pensando naquele momento?' Os mediadores elaboraram mais facilmente relatos que justificavam suas atitudes e pensamentos, enquanto os visitantes demonstraram ser mais hábeis em narrar os significados e as descrições de suas experiências.

Percebeu-se uma clara distinção de comportamento dos participantes, ao compararmos as entrevistas estimuladas por vídeo e aquelas acompanhadas por fotos. Nestas últimas, os entrevistados tendiam a uma conduta mais ativa; descreviam prontamente o contexto de cada foto, verbalizando o que haviam feito e justificando atitudes e/ou significados. Nas entrevistas com vídeo, ao contrário, o comportamento era menos ativo; em geral, só após assistir a todo o fluxo de acontecimentos registrado nas imagens, o participante respondia às perguntas.

A visita à exposição de um museu de ciências proporciona indícios sobre o ambiente bem diferentes para cada visitante, no que diz respeito a ambientação, unidades expositivas, ações realizadas por outros visitantes, pessoas ao seu redor, entre outros. Para o visitante, fotografias que captam esses momentos podem ser fortes referências, porque possibilitam que ele se veja em interação com unidades expositivas e outras pessoas. Portanto, o uso de fotos representa uma boa adaptação da LE em estudos sobre aprendizagem em museus de ciências.

A entrevista com fotos digitais acontece de forma dinâmica. Após algumas imagens iniciais, os participantes compreendem o procedimento e passam a responder com facilidade às questões. Em nossa pesquisa, freqüentemente não era sequer necessário formular a pergunta; ao ver uma nova imagem, o entrevistado já verbalizava seus comentários. E quando não tinha o que dizer sobre uma foto específica, bastava acessarmos a seguinte. Com relação ao vídeo, ao contrário, quando o indivíduo não se manifesta, a atmosfera da entrevista pode se tornar negativa, pois o tempo que o entrevistador 
leva para procurar uma nova seqüência que evoque comentários pode cansar ou aborrecer o participante.

Do ponto de vista operacional, o uso de imagens digitais facilita a realização das entrevistas nas escolas, porque prescinde de televisão e videocassete, equipamentos nem sempre disponíveis nesses locais. Tal aspecto confere maior autonomia ao pesquisador e maior independência das entrevistas em relação a problemas operacionais de última hora. As imagens são exibidas em laptop e apresentadas em formato 'tela cheia'. No teste piloto, o próprio recurso - imagens digitais em laptop - foi visto como um processo interessante aos olhos dos participantes, ajudando a estabelecer um clima amistoso na ocasião da entrevista. Cópias das fotos foram posteriormente enviadas por e-mail aos participantes, como forma de agradecimento.

As fotos digitais em substituição ao vídeo, este último um recurso tradicional na LE, mostraram-se eficazes e eficientes com os visitantes de museus de ciências. Eficazes porque proporcionam referências sólidas de cada interação com as unidades expositivas e geram dados de qualidade, sem a desvantagem de proporcionar indícios extras; e eficientes por simplificarem procedimentos, conferindo maior autonomia ao pesquisador e fruição ao processo de entrevista.

Entendemos que a principal contribuição da LE, nos museus de ciências, é facilitar o participante a expressar o significado de suas experiências, assim como as razões para suas ações e escolhas ao longo da visita. A seqüência de fotos, no caso dos visitantes, e o vídeo, no caso dos mediadores, trazem para a avaliação muitas situações de aprendizagem que ocorrem na visita e que certamente escapariam a outras metodologias. Neste sentido, o uso da LE pode trazer subsídios relevantes para a pesquisa sobre aprendizagem em museus de ciências.

\section{REFERÊNCIAS BIBLIOGRÁFICAS}

Aaltonen, $\mathrm{K}$. 2001

Anderson, $M$. 1985

Appleton, K. 1993

Biggs, S. et al. 1993
Use of the stimulated recall-method as a reflective tool in eliciting practical knowledge of an experienced nursing teacher. Trabalho apresentado na European Conference on Educational Research 2001, 5-8 September, Lile, France.

Some evidence on the effect of verbalization on process: a methodological note. Journal of Accounting Research, n. 23, p. 843-52.

What makes lessons different? A comparison of a student's behaviour in two science lessons. Research in Science Education, n. 23, p. 1-9.

Methodological issues in judgment and decision-making research: concurrent verbal protocol validity and simultaneous traces of process. Journal of Behaviour Decision Making, n. 6, p. 187-206. 
Bloom, B. S. 1953

Boritz , J. E. 1986

Bosher, S. 1998

Butefish, W. L. 1990

Calderhead, J. 1981

Ericson, K.; Simon, $\mathrm{H}$. 1996

Ericson, K.; Simon, H. 1980

Fernández, M.;

Ruíz, E. M. ene. 1996

Gaier, E. L. 1954

Gass, S.; Mackey, A. 2000

Marland, P. W.;

Edwards, J. 1986

Masahiko, O.; Norihiko, K. Sep. 1992

Nisbert, R.; Wilson, T. 1977

Oppenheim, A. N. 1992

Ritchie, S. M. 1999

Russo, J. et al. 1989

Schank, R. C.;

Abelson, R. 1977

Sharp, R.; Green, A. 1975

Stevens, R.; Hall, R. 1997

Stevenson, A.; Bryden, $M$. 1991
The thought process of students in discussion. In: French, S. J. (ed.).

Accent on teaching: experiments in general education.

Nova York, Harper \& Brothers.

The effect of research method on audit planning and rewiew judgements. Jounal of Accounting Research, n. 26, p. 335-48.

The composing process of three Southeast Asian writes at the post-secondary level: an exploratory study. Journal of Second Language Writing, n. 7, p. 205-41.

Science teachers' perceptions of their interactive decisions. Journal of Educational Research, v. 84, n. 2, p. 107-14.

Stimulated recall: a method on teaching.

British Journal of Educational Psychology, n. 51, p. 211-7.

Protocol analysis: verbal reports as data.

$3^{\mathrm{a}}$ ed. Cambridge MA, MIT Press.

Verbal reports as data.

Psychological Review, n. 87, p. 215-51.

Empleo del videodisco en la formación de profesores: el CCP. Revista PIXEL-BI: . Revista de Medios y Educación, n. 6.

A study of memory under conditions of stimulated recall, J. Gen. Psychol, n. 50, p. 147-53.

Stimulated recall methodology in second language research. Mahwah/Nova Jérsei, Lawrence Erlbaum Associates.

Students' in-class-thinking.

Instructional Science, n. 15, p. 75-88.

The role of metacognitive knowledge and aptitude in arithmetic problem solving. Psychologia: An International Journal of Psychology in the Orient, v. 35, n. 3, p. 164-72.

Telling more than we can know: verbal reports on mental processes. Psychology Review, n. 84, p. 231-59.

Questionnaire design and attitude measurement. Londres/Washington.

The craft on intervention: a personal practical theory for a teacher's within-group interactions. Science Education, n. 83, p. 213-31.

The validity of verbal protocols. Memory and Cognition, n. 17, p. 759-69.

Scripts, plans, goals, and understanding: an inquiry into human knowledge structures. Hillsdale NJ, Earlbaum Assoc.

Education and social control.

Londres, Routledge and Kegan Paul.

Seeing tornado: how video traces mediate visitor understandings of (natural?) phenomena in a science museum. Science Education, v. 81, n. 6, p. $735-48$.

The national museums of Scotland's 1990 discovery room: an evaluation. Museum Management and Curatorship, v. 10, p. 24-36. 
MÉTODO DA LEMBRANÇA ESTIMULADA

Stevenson, J.

1991

White, $\mathrm{P}$.

1980
The long-term impact of interactive exhibits.

International Journal of Science Education, v. 13, n. 5, p. 521-31.

Limitations on verbal reports of internal events: a refutation of Nisbert and Wilson and of Bem. Philosophical Review, n. 87, p. 105-12.

Recebido para publicação em novembro de 2002.

Aprovado para publicação em março de 2003. 